\title{
De Italia al Perú. La obra litográfica de Carlo Fabbri
}

From Italy to Peru. The litographic work of Carlo Fabbri

Sofía Pachas Maceda ${ }^{1}$

\section{Resumen}

Este artículo trata de la obra litográfica de uno de los más talentosos artistas italianos que llegaron al Perú en el siglo XIX, Carlo Fabbri. Su singular obra, publicada en revistas como el reconocido semanario El Perú Ilustrado, capta la atención por las originales composiciones a manera de reportajes visuales y sus amenas escenas en las que la hilaridad no necesita de palabras. Con fino y meticuloso estilo, las litografías de Fabbri merecen ser consideradas entre las mejores de esta prolífica etapa para las artes gráficas peruanas.

Palabras clave: artistas italianos Perú, litografía, revistas ilustradas siglo XIX, humor, retratos

1 Docente nombrada de la Facultad de Letras de la Universidad Nacional Mayor de San Marcos. Contacto: docenciaskpm@gmail.com 


\begin{abstract}
This article deals with the lithographic work of Carlo Fabbri, one of the most talented Italian artists who came to Peru during the XIXth century. His remarkable works were published in magazines such as the well-known weekly El Perú Ilustrado (Illustrated Peru), in which he captures attention with original compositions that seem to be illustrated reports and pleasant scenes that need no words to provoke laughter.
\end{abstract}

Keywords: Italian artists Peru, lithography, illustrated magazines XIX century, humour, portraits

$$
* * *
$$

\title{
Introducción
}

Miembro de una de las colonias extranjeras más numerosas y activas del Perú decimonónico, el italiano Carlo Fabbri arriba al Perú en una época de especial relevancia en el desarrollo de la prensa ilustrada nacional. Con veinte años de edad, formación en la Academia de Bellas Artes de Brera y experiencia en talleres gráficos italianos, no transcurre mucho tiempo para que el apellido Fabbri figure dentro de la plana de colaboradores de revistas como El Perú Ilustrado, La Ilustración Americana y La Ilustración Sud Americana. El lapso

138 comprendido entre 1889 y 1892 es el más productivo de la carrera artística de Fabbri. Durante esos años, ejecuta retratos y avisos comerciales, pero es con las litografías incluidas en las secciones "Álbum Humorístico" y "Noticias de Actualidad" con las que se distingue de sus colegas litógrafos de El Perú Ilustrado. Abigarradas composiciones en las que narra la actividad social y cultural, fino humor no exento de crítica y la figura femenina voluptuosa se convierten en las cons- 
tantes que lo diferencian. Este artículo destaca estas particularidades y las analiza formalmente confrontándolas con el contexto histórico social de la Lima de fines del siglo XIX.

\section{El viaje, cambiando el rumbo}

Forli es una de las nueve provincias de la región italiana de Emilia-Romaña. Ubicada en el nororiente del país, en el siglo XIX, era uno de los estados que vivió en zozobra a causa de las constantes luchas a raíz del proceso histórico conocido como Il Risorgimento. ${ }^{2}$ Allí nació Carlo Fabbri el 2 de junio de 1867, hijo de Ulisse Fabbri y Clementina Menichetti. Luego de realizar estudios escolares en Milán, ingresó a la Academia de Bellas Artes de Brera donde estudió pintura y diseño, guiado por los profesores Casnedi, Bertini, Brambilla, Borghi y Caironi (Leonardini 2003: 20). Quizá la difícil situación económica familiar lo incentivó a aprender grabado, disciplina más rentable, dado su uso en las labores de imprenta.

Con dicho bagaje artístico, experiencia en talleres tipolitográficos italianos y con expectativas de un futuro mejor, emprende viaje al Perú aproximadamente en 1887. Aunque los tiempos no eran los más propicios, pues todavía estaba muy reciente la guerra con Chile, la posterior invasión, y la guerra civil entre Iglesias y Cáceres. Eran los años de lo denominado por Basadre como "Reconstrucción Nacional". Aun así, Carlo contaba con la protección familiar y, así, en Lima, se reúne con su hermano Pietro, con quien funda, un año después, el establecimiento tipolitográfíco Fabbri Hermanos.

2 Il Risorgimento o la unificación italiana fue el movimiento político y social que reunió a varios estados de la península itálica con el deseo de lograr la unificación en un único Estado de Italia. 
La apertura de un negocio por parte de italianos en la segunda mitad del siglo XIX era habitual en Lima. A diferencia de otros países en los que la migración italiana había respondido a un proyecto de colonización, en el Perú, este tipo de iniciativas gubernamentales fracasó y lo que hubo fue una migración espontánea desarrollada por los propios migrantes que, luego de un período de establecimiento, traían a sus compatriotas; de este modo, se formaban redes familiares y comerciales, las cuales también se activaban de manera inversa cuando, luego de años de trabajo, algunos de ellos decidían volver a su patria para pasar sus últimos años de vida en su tierra natal. Así lo explica Giovani Bonfiglio cuando señala que:

"La observación de numerosos casos de cadenas migratorias establecidas entre Italia y el Perú, indican que se trataba de una suerte de vasos comunicantes entre ambas orillas marítimas, a través de las cuales circulaban migrantes y se establecían contactos que eran activados en ambos sentidos, es decir de ida y vuelta" (1994: 87).

Al parecer, la labor de organización del negocio impidió a nuestro protagonista dedicarle tiempo a su espíritu creativo, pues no hemos localizado colaboraciones litográficas en los primeros años de su estadía. Sin embargo, en 1889, este período de inactividad artística cambió, pues Fabbri encontró la manera de sintonizar ambas actividades, la del litógrafo y

140 la de comerciante. Así, este año, llegó al taller de Peter Bacigalupi, centro de operaciones de El Perú Ilustrado, una de las más importantes revistas del período. Allí colaboró con entregas que sobresalen por la abigarrada y sinuosa línea.

Carlo Fabbri es un eslabón más en la cadena de italianos que han contribuido con el arte peruano. Esta influencia data del período virreinal cuando, en 1575, arribó el jesuita Bernardo 
Bitti, al que, posteriormente, se le unieron Mateo Pérez de Alesio y Angelino Medoro, quienes formaron la triada que influyó de manera significativa en la pintura del siglo XVI. Luego de la Independencia, los italianos y sus descendientes continuaron aportando a la actividad artística; el más paradigmático caso es el del pintor Juan Lepiani, peruano de ascendencia italiana, cuyos lienzos de temática histórica han contribuido a formar el imaginario de varias generaciones de peruanos. Este asunto ha sido tratado con amplitud por la historiadora de arte Nanda Leonardini, quien lo desarrolla en su tesis doctoral Los italianos y su influencia en la cultura artística peruana en el siglo XIX, de la que extraemos las siguientes líneas:

La influencia italiana en el arte decimonónico peruano es determinante. Se deja sentir con fuerza debido a varios aspectos que se traducen en la arquitectura, la escultura, la pintura, la litografía y la difusión del arte, siendo las dos primeras disciplinas trascendentes en la formación de la estética urbana del siglo XIX a través de una serie de inmuebles públicos y particulares, así como de obras escultóricas en mármol que decoran la arquitectura urbana y funeraria dentro de conceptos clásicos europeos (1998: 192).

En el caso de la litografía, Fabbri es el máximo representante italiano activo en el siglo XIX.

\section{Colaboraciones en revistas limeñas}

La obra litográfica de Carlo Fabbri tiene su mejor momento entre los años 1889 y 1892. En ese período, colaboró con tres revistas: El Perú Ilustrado, La Ilustración Americana y La Ilustración Sud Americana. Aunque toda su obra es de una calidad impecable, distinguimos un momento de especial creatividad en las litografías publicadas en el semanario El Perú 
Ilustrado. Por ello, nos referiremos primero a su labor en las dos últimas revistas, pues este artículo tiene como propósito destacar lo particular de la propuesta de Fabbri en el medio fundado por el ítalo-estadounidense Peter Bacigalupi, El Perú Ilustrado.

Luego de 1889, cuando formaba parte del grupo de litógrafos de El Perú Ilustrado, volvemos a localizar su firma en 1891, en las páginas de La Ilustración Americana. Allí, un grupo de retratos, entre los que sobresale el del literato $\mathrm{Ma}$ nuel González Prada (imagen 1) y firmados por Evaristo San Cristóval, ${ }^{3}$ llevan, en el otro extremo de la imagen, la firma Fabbri Hermanos. De esta manera, se confirma la relevancia que el centro litográfico tenía por esos días, pues al bien acabado dibujo del destacado San Cristóval se une la calidad de impresión de la empresa familiar italiana, que, por esos días, ocupaba el 317 de Baquíjano.

En el tercer número, del 1 de agosto de 1891, La Ilustración Americana cambió el encabezado de Evaristo San Cristóval por uno de nuestro protagonista. Como en otros medios escritos de la época, Fabbri eligió un lenguaje clásico, sobrio y preciso para sintetizar la temática abordada en la revista: li-

3 El litógrafo Evaristo San Cristóval (Cerro de Pasco, 1848-Lima, 1900) se inicia en el arte del dibujo con el profesor italiano Leonardo Barbieri, mientras su labor como litógrafo fue aprendida de manera autodidacta. A partir de 1886, apareció en medios como El Perú Ilustrado, El Boletín de Lima, El Rímac, Perlas y Flores, entre otros. Asimismo, se animó a iniciar proyectos editoriales de manera independiente; algunos de ellos son El Perú Artístico (1893) y la revista de La Exposición de Lima, organizada en 1892 por la Municipalidad de Lima. La obra litográfica de San Cristóval se caracteriza por su gran calidad plástica reflejada en su perfecto dibujo y en el uso de una línea firme (Pachas Maceda 2009: 5). 


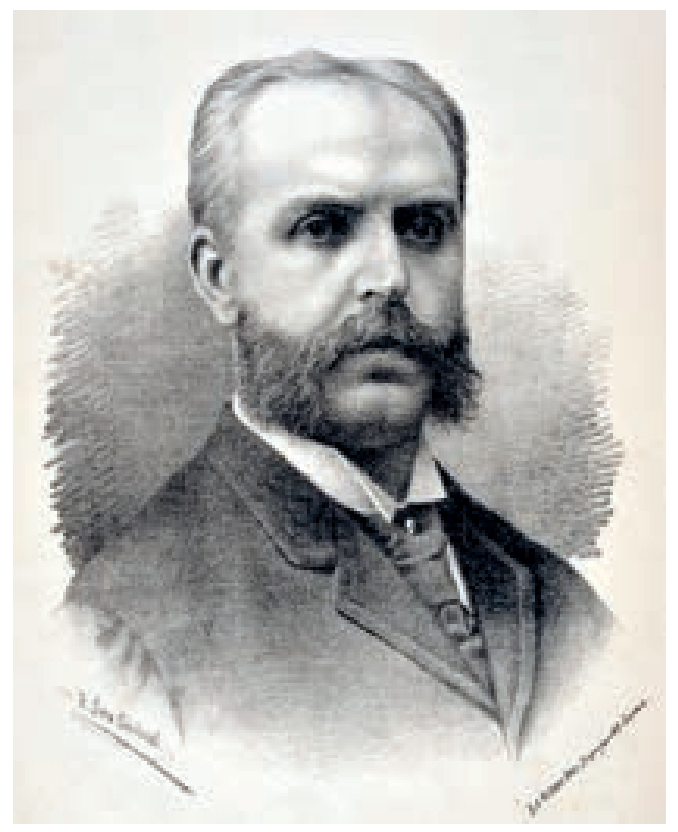

Imagen 1

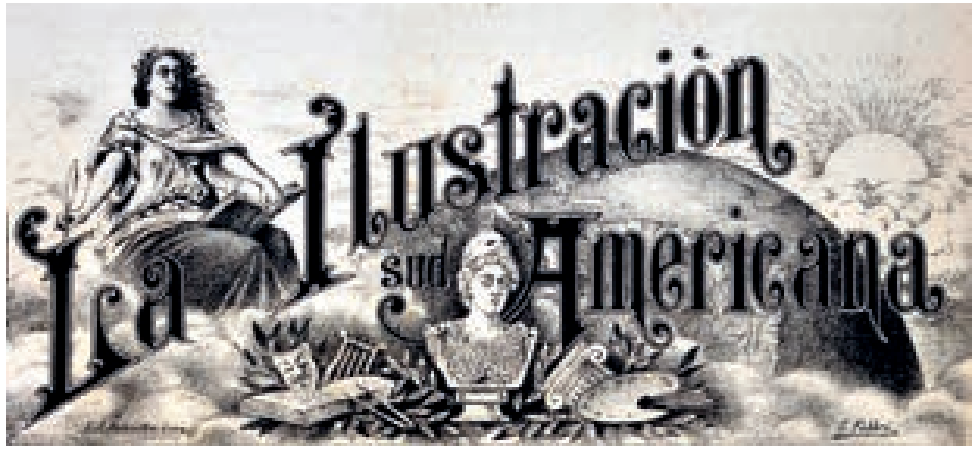

Imagen 2 
teratura (libro abierto), teatro (máscara), música (lira), arquitectura (compás y capitel), escultura (busto) y pintura (paleta y pinceles). Todos estos objetos relacionados con las artes, ciencias y letras se encuentran dispuestos ante la silueta de un globo terráqueo, un sol que asoma — símbolos del conocimiento que ilumina al mundo-y una mujer que, colocada entre las palabras que forman el nombre de la revista, representaría a la escritura y lectura — quehaceres a través de los cuales se difunden los saberes-.

Para setiembre de 1891, ve la luz La Ilustración Sud Americana y lo hace con el mismo encabezado al que nos hemos referido, al que solo se le añade la palabra "Sud" (imagen 2). Sin ningún comentario sobre su labor en este nuevo medio, en el mismo número, también se aprecian los retratos Una limeña y el del poeta Teobaldo E. Corpancho, firmados por Fabbri. En las siguientes entregas, continúa colaborando, aunque de manera esporádica; probablemente, las responsabilidades del negocio familiar impedían la frecuencia.

Estas obras son retratos convencionales, pero, no por ello, carentes de belleza; estos muestran su esplendor en figuras femeninas como Una limeña, Una chiclayana y Señorita Edelmira Quiroga (imagen 3). Se seguía una costumbre habitual de la época por la que los retratos femeninos, a veces, eran publicados sin consignar el nombre de la retratada; en otros casos, se hacía referencia a ellas, porque la dama acababa de fallecer y era necesario rendirle un último tributo a la laboriosa matrona, o a la bella e infortunada joven que había partido tempranamente, como en el caso de la señorita Edelmira Quiroga. De manera esporádica, localizamos algunas halagadoras líneas al trabajo litográfico de Fabbri, como las siguientes, publicadas a propósito de Una chiclayana: "Cuanto al dibujo, 
Sofía Pachas
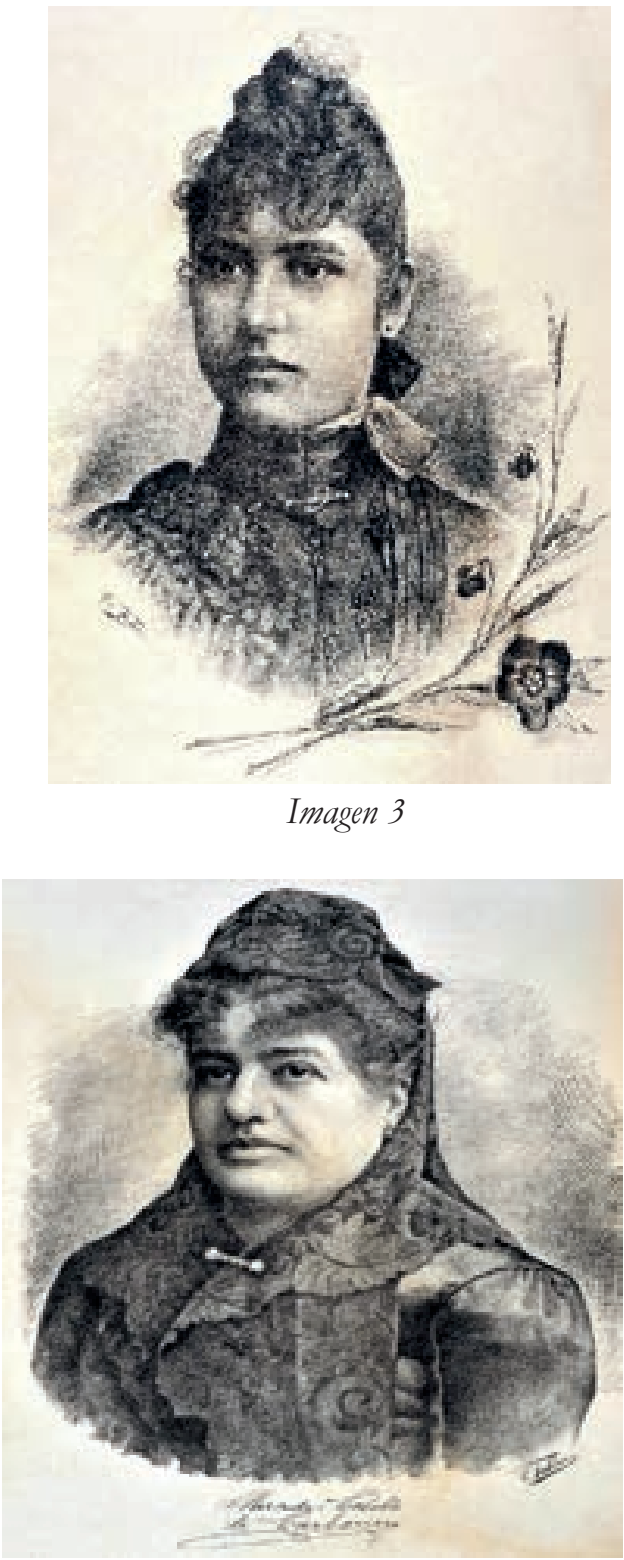

Imagen 4 
nada podemos agregar a lo que tenemos dicho, basta indicar que se debe al lápiz de uno de los más hábiles artistas: Carlos Fabbri" (1891: 39).

El parecido físico lo constatamos cuando se trata de una figura pública captada por otros medios. Tal es el caso de la reconocida literata Mercedes Cabello de Carbonera (imagen 4), a quien representa con primoroso velo que enmarca un rostro de mirada sosegada. Este velo de encaje, junto con el broche, son elementos de distinción, sobrios, pero de indudable elegancia que hacen las veces de atributos para diferenciar estratos sociales.

En esta misma temática, destaca el retrato del capitán de navío Manuel A. Villavicencio (imagen 5), a quien se observa como parte de una elaborada composición en la que la imagen del militar se rodea de hojas de laurel, que aluden a su destacada actuación en la guerra del Pacífico, y un ángel que sostiene, con evidente dificultad, el escudo y la bandera del Perú. En la parte inferior, además, se observa La Unión, corbeta que estuvo bajo su mando en el conflicto bélico.

Es interesante destacar que tanto los retratos de héroes relacionados con la guerra del Pacífico como las imágenes de paisajes, ciudades del interior del país o prósperos negocios tienen implícito un mensaje optimista del Perú, un deseo de

146 recordar la valentía de aquellos quienes ofrendaron sus vidas por el bien patrio, mientras que las litografías de asuntos urbanos mostraban la reconstrucción ya encaminada.

\section{E1 mejor momento creativo}

Sin dejar de apreciar la calidad plástica de las colaboraciones reseñadas, distinguimos, en la vida artística de Carlo Fab- 


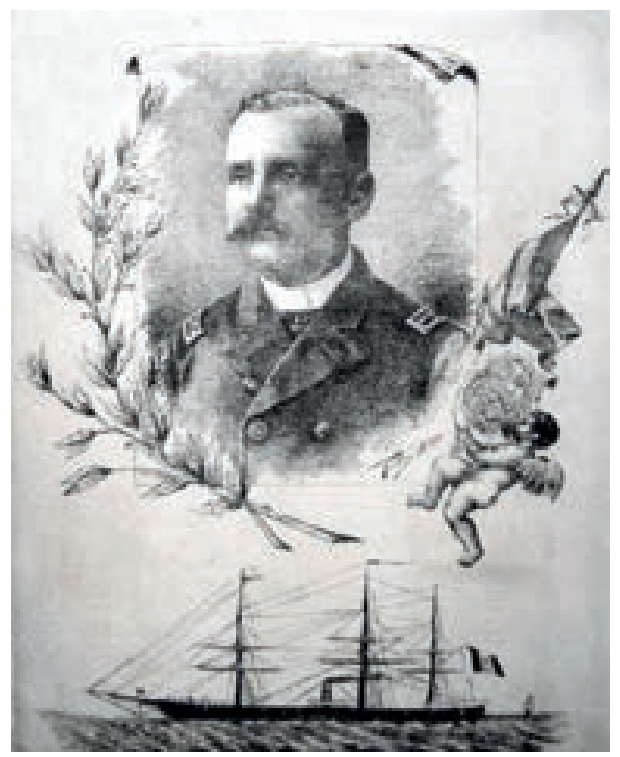

Imagen 5

bri, una etapa de especial creatividad en 1889, año en el que inicia su labor artística en el Perú colaborando, de manera frecuente, con El Perú Ilustrado. La relevancia de este semanario puede constatarse en el interés que concita entre los investigadores actuales, quienes lo han tomado como base para sus trabajos gracias a la importante información escrita que presenta y al universo visual que exhibe. Fundado en 1887 por Peter Bacigalupi, este medio se consolidó en el ámbito periodístico por la calidad de intelectuales que escribían, pero también por su calidad artística: el arte litográfico es parte fundamental de esta revista, la cual, inclusive, favorece a esta disciplina, debido a que los talleres abren sus puertas a jóvenes aficionados. Estos forman una generación de litógrafos, entre los que figuran David Lozano, Belisario Garay y Luis Melagarejo. 
Sobre la relevancia de la litografía en la prensa decimonónica, el investigador Marcel Velázquez ha señalado las posibilidades de este "entramado gráfico" al decir que:

"[ellas] contribuyen con la formación de una comunidad que se autorreconoce mediante imágenes realistas" que "[intensifican] la experiencia de la modernidad de los lectores y potencia la reconstrucción nacional mediante la fijación de imágenes de la comunidad material y espiritual y el re-conocimiento visual de lo propio" (2009: 27). Así, la obra litográfica de Carlo Fabbri se engarza en esta historia gráfica del Perú republicano y es 1889 el año decisivo del posicionamiento de su apellido en menesteres artísticos; ello, muy probablemente, repercute de manera positiva en sus posteriores actividades comerciales. Aunque una de sus primeras entregas fueron tres vistas de Costa Rica copiadas de fotografías - manera de trabajar muy difundida entre sus colegas-, pronto su obra marcará la diferencia con novedosas propuestas en avisos comerciales, páginas humorísticas y noticias de actualidad.

Del primer rubro, señalaremos dos casos. El primero se trata de un elaborado diploma otorgado al Establecimiento de Petróleo Zorritos publicado a doble página y que sorprende por el despliegue de líneas y formas onduladas; en este, una virgen y un grupo de ángeles irrumpen en una recargada composición que, más que propaganda, parecería una pintura barroca. Por su parte, causa sorpresa ob-

148 servar el segundo aviso, publicado mes a mes; se trata del Calendario de Backus y Johnston. Cervecería y Fábrica de Hielos de los Descalzos (imagen 6). En la parte superior de este aviso, llaman la atención dos sacerdotes en amena plática con dos botellas y vasos de por medio; uno de ellos, en actitud bastante desinhibida, tiene a su lado otro par de botellas de la conocida bebida enfriándose. 
Otra sección en la que se aprecian las originales propuestas de Fabbri es "Álbum humorístico". Desde un orondo cerdo durmiendo plácidamente, titulado El sueño del justo, hasta una jocosa escena que narra algunos posibles contratiempos de emprender Un viaje en el mar. Sin embargo, hemos seleccionado el "Álbum humorístico" titulado Cuadros al natural (imagen 7), publicado el 16 de marzo de 1889 para comentar la manera en que la imagen femenina era representada.

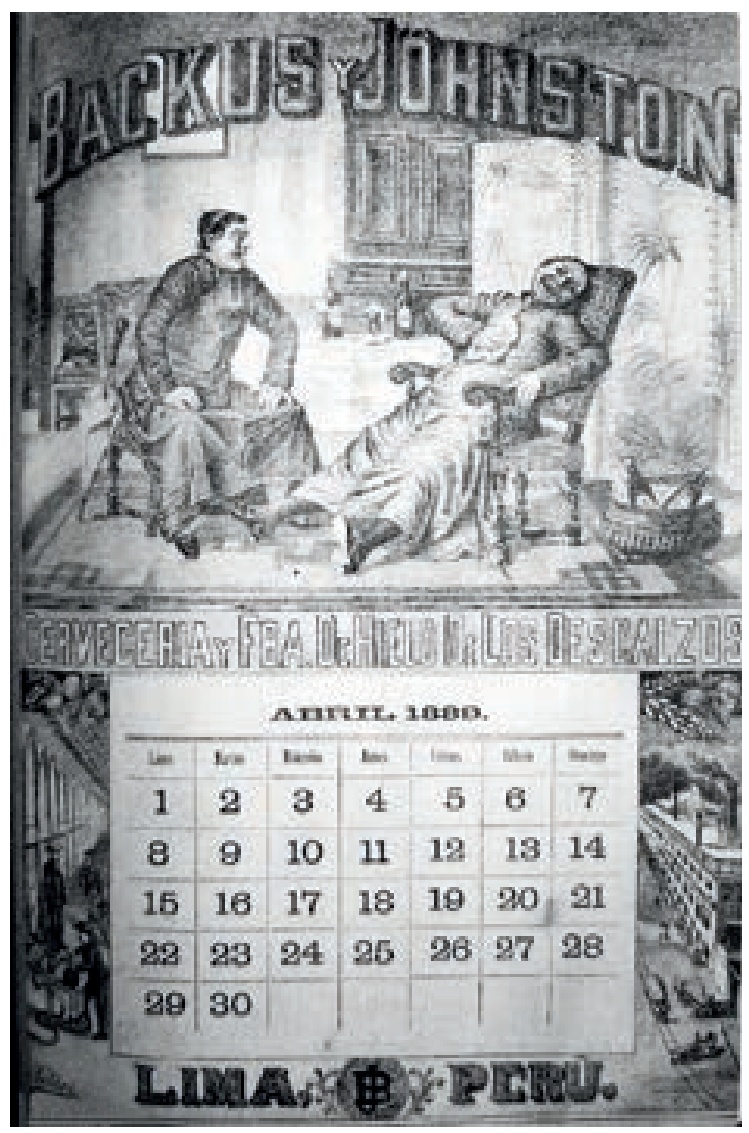




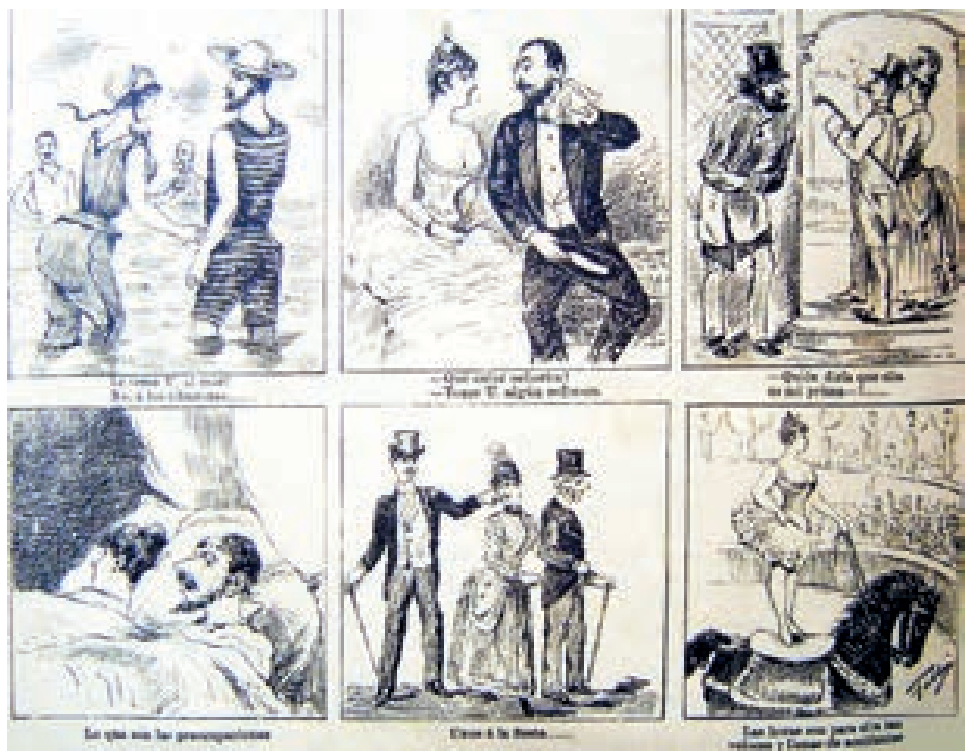

\section{Imagen 7}

Impresa en la mitad superior de una página del semanario, la litografía narra visualmente, pero también con escuetas frases que, a manera de diálogos o rótulos, son incluidos debajo de cada imagen. Son seis las escenas desvinculadas de una historia en particular, pero que tienen como eje a la mujer. En las dos primeras, son ellas las "víctimas" acosadas por la mirada masculina; en las siguientes cuatro, son ellas las victimarias - activas o pasivas - que representan los defectos de la mujer: interesada, despreocupada, coqueta y manipuladora. Estos ya eran asuntos tratados en relatos publicados en medios como El Correo del Perú en la década de $1870^{4}$ o en

4 Este asunto ha sido investigado por Elizabeth Vilca en La imagen femenina: una visión contradictoria en el discurso del sujeto ilustrado en El Correo del Perú (1872), quien destaca escritos en los que se pone de relieve los deseos 
obras literarias peruanas en las que personajes como Blanca Sol (1888), de Mercedes Cabello de Carbonera, representan los límites a los que podrían llegar las mujeres.

Con esta obra, Carlo Fabbri trasciende los linderos del cronista visual para asumir el papel de crítico de costumbres de su tiempo, lo cual no es una prerrogativa del artista italiano. Por esa misma época, en México, José Guadalupe Posada colaboraba en la revista La Patria Ilustrada indagaba también en algunos "vicios" sociales en los que solía incurrir la mujer, como el caso de la influencia negativa de la moda. Este asunto no fue ajeno a los medios de prensa peruanos: habría que recordar el impacto que tuvo la incursión del traje francés, a tal punto que las limeñas optaron por él en desmedro del traje tradicional de la tapada, cambio que les quitó libertad de desplazamiento. ${ }^{5}$

del sujeto hegemónico masculino hacia la mujer (moralidad, sensibilidad, sumisión y una educación controlada), los cuales, a veces, difieren de las propuestas de progreso venidas desde Europa.

5 Precisamente, una francesa, Flora Tristán, queda gratamente sorprendida de la libertad de la que gozaban las limeñas gracias a este traje cuando escribe, en Peregrinaciones de una paria:

Después de lo que acabo de decir sobre el vestido y los usos de las limeñas se concebirá fácilmente que deben tener un orden de ideas diferentes al de las europeas quienes desde su infancia son esclavas de las leyes, de las costumbres, de los hábitos, de los prejuicios, de las modas, de todo, en fin. Mientras que bajo la saya la limeña es libre, goza de su independencia y se apoya confiadamente en esta fuerza verdadera que todo ser siente en sí cuando puede proceder según los deseos de su organismo. (Tristán 2003: 497). 
La representación femenina no pasa inadvertida en las litografías de Fabbri, pues este Cuadro al natural no es el único en el que la belleza de la mujer es la protagonista. Lo localizamos también en otra obra titulada El carnaval (imagen 8) en la que la silueta femenina - exuberante y curvilínea- marca el eje vertical de la obra que guía la mirada hasta el título principal donde otra bella joven con insinuante escote se asoma.

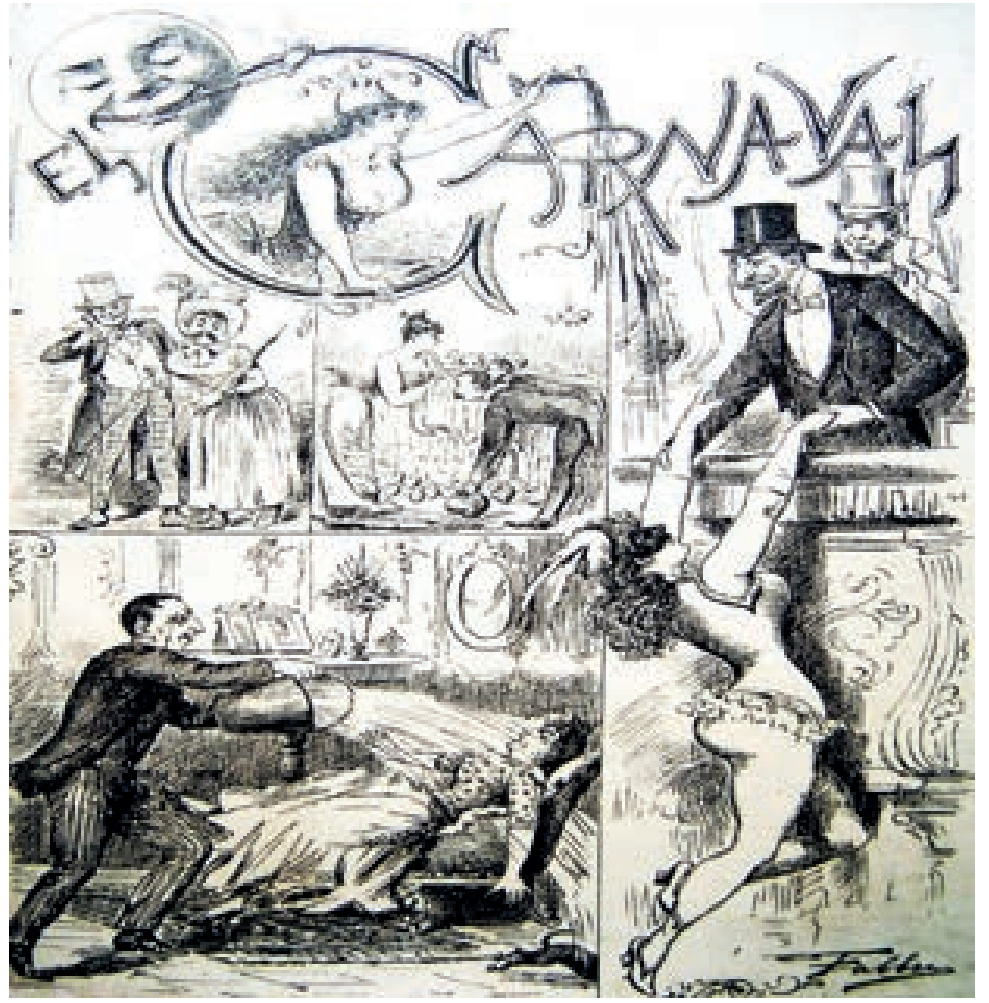

Imagen 8 
No obstante, son sus "Dibujos del natural" los que se vuelven una característica para distinguir la obra de Carlo Fabbri. En ellos, representa actividades sociales, las cuales son plasmadas, a página entera, en composiciones que comprenden varias escenas rotuladas con un título general. En esas entregas, destaca su interés por captar amplios espacios y numerosos grupos de personas; con ello, rompe el esquema de las litografías publicadas en El Perú Ilustrado, en las que la figura humana - en solitario o en grupo- pocas veces formaba parte del paisaje citadino o rural. Buenos ejemplos de estas obras son Palacio de la Exposición. Fiestas del 28 de julio, Vista del banquete de 400 cubiertos ofrecidos a Cáceres, y Consagración del ilustrísimo y reverendísimo arzobispo de Lima (imagen 9). Esta última litografía tiene una especial distribución del espacio. La página entera es dividida en tres partes; en el centro, dentro de un óvalo, se aprecia el retrato del arzobispo Dr. Manuel Antonio Bandini, estratégicamente colocado sobre el púlpito, en alusión al importante rol de consejero y guía para una sociedad como la limeña. Destacan, además, las vistas externa e interna de la Catedral, en las que la fachada y el retablo mayor lucen rodeados de multitud de fieles. 


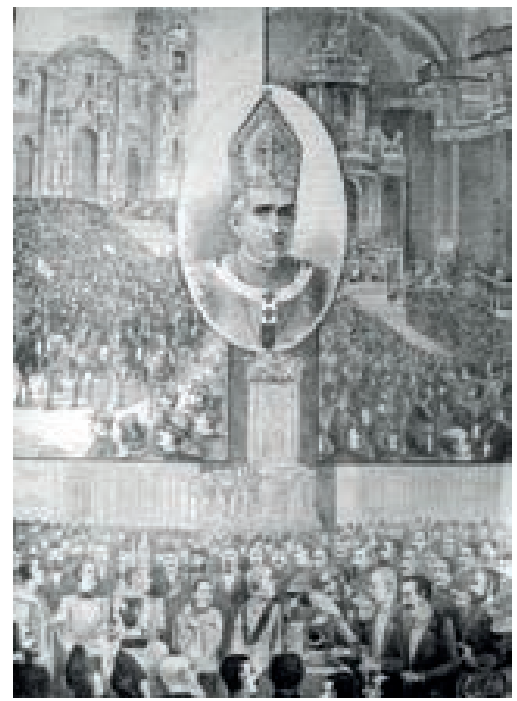

Imagen 9

Aunque la litografía Antiguo Teatro Principal (imagen 10) pertenece al rubro de noticias de actualidad, no es difícil percatarse de la particular manera de narrar, con un estilo caricaturesco que, de alguna manera, lo hermana con la obra del norteamericano L. Williez, quien, en 1855, publicó el álbum Adefesios con 24 caricaturas políticas litografiadas. Antiguo Teatro Principal es una de las más elaboradas colaboraciones de Fabbri. Publicada a página entera, trata un asunto relacionado con el Teatro Principal, la Municipalidad de Lima y

154 Peter Bacigalupi, propietario de El Perú Ilustrado, cuyo retrato sobresale en la parte superior y en el lado inferior derecho. Estos datos se corroboraron con la información colocada a los pies de la imagen. 


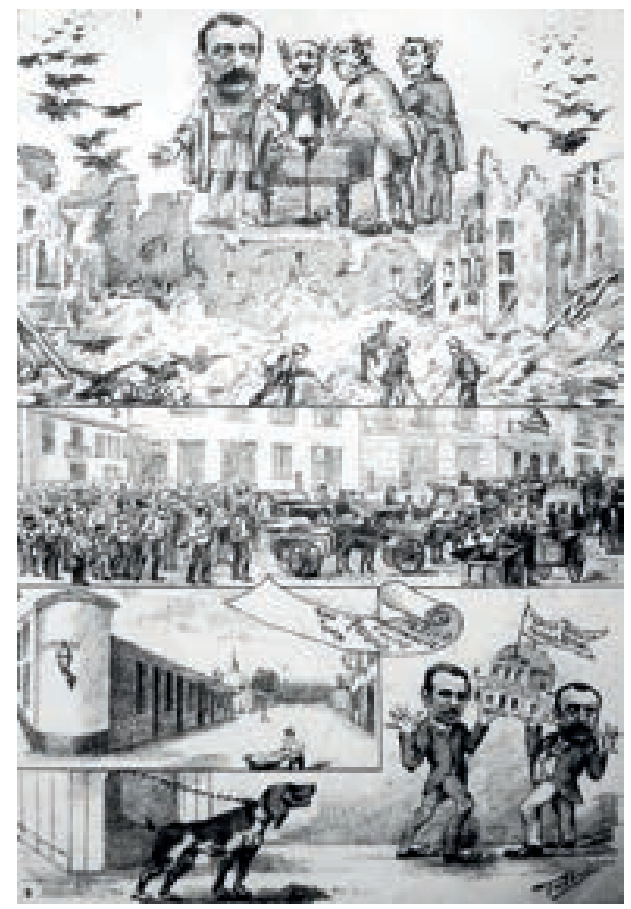

Imagen 10

El asunto teatral ofrece a Fabbri la pauta para elaborar esta litografía como si se tratase de los actos de una obra; incluso las enumera. Dividida en franjas horizontales, la escena superior e inferior son las dominantes, dado el espacio empleado para ellas. Para introducirnos en la noticia, cita la historia conocida como "El huevo de Colón", relato incluido en la Historia del Nuevo Mundo (Verona, 1565) de Girolamo Benzoni, en el que el navegante italiano soluciona un problema en apariencia imposible de resolver: poner en pie un huevo. Sin embargo, merced a su inteligencia y astucia, logra superar el reto ante la incredulidad y confusión de los testigos, pues el protagonista rompe el huevo para lograr el cometido. Demuestra así Colón que, después de hecha y vista la hazaña, cualquiera sabe cómo hacerla. 
En la obra, Fabbri convierte a Bacigalupi en un Colón moderno - con vestimenta incluida - ante la mirada de tres hombres con orejas de asno que, sin duda, representan la incapacidad para solucionar un asunto relacionado con el Teatro Principal, el más antiguo de Lima. Desde el incendio de 1883, el local y sus alrededores habían sido abandonados. Gracias a la intervención del alcalde César Canevaro — quien había ordenado la limpieza del lugar- y, luego, de la sociedad de Bacigalupi y Parrinello — quienes dieron el dinero para reconstruir totalmente el teatro- el lugar fue reedificado íntegramente de madera; por ello, la palabra "portátil" luce en el banderín de la parte superior de la maqueta que cargan los socios. Esta reapertura brinda la oportunidad de contar con una nueva sala en la que se podría admirar obras de calidad en la capital del Perú, ciudad en la que pululaban los gallinazos que varios artistas viajeros ya habían captado y a los que Fabbri tampoco se muestra indiferente.

\section{Las dos orillas}

Quince años después de iniciada la sociedad con su hermano Pietro, esta se disolvió en 1902. Asumió, entonces, Carlo la total responsabilidad de la empresa y lo que siguió es una ardua labor plasmada en numerosos libros, informes y variedad de documentos que se elaboraron en su establecimiento tipolitográfico, algunos de los cuales llevaban insertas composiciones, planos y mapas que realzaban la importancia del texto. La calidad de las publicaciones no es fortuita si reparamos que, para entonces, su establecimiento contaba con un personal artístico y obrero de cien personas, además de una excelente maquinaria y materia prima importada de Italia (Litografía y Tipografía Fabbri 1906) 
(imagen 11). Ya para entonces la fama de Litografía y Tipografía Fabbri trascendía las fronteras, pues, como asiduo concurrente a las ferias internacionales (París, Milán y Madrid), logró el máximo galardón en la de Londres, en 1906. Cuatro años después, es condecorado por la Municipalidad de Lima con una medalla de honor en reconocimiento a su labor (El Comercio 1910: 1).

En su local, ubicado en Mercaderes $140,{ }^{6}$ también se elaboraba una amplia variedad de etiquetas de colores para distintos productos (vinos, cigarros, etcétera). En este último rubro, destacan dos series de barajas españolas encargadas por dos compañías de cigarros: Roldán y La Mutua, en los cuales se aprecia la calidad plástica y técnica que alcanza su taller. ${ }^{7}$ No satisfecho con el éxito logrado en el campo de las artes gráficas, a partir de la década del veinte incursiona en el negocio de la construcción y, así, surge Edificio Fabbri S.A. Gracias a su inquieta personalidad, el trabajo en sus negocios no impide

6 En 1926, trasladó su local a la calle Rifa 360.

7 Algunas de estas barajas estuvieron colgadas en la web en 2010. 
De Italia al Perú. La obra litográfica de Carlo Fabbri

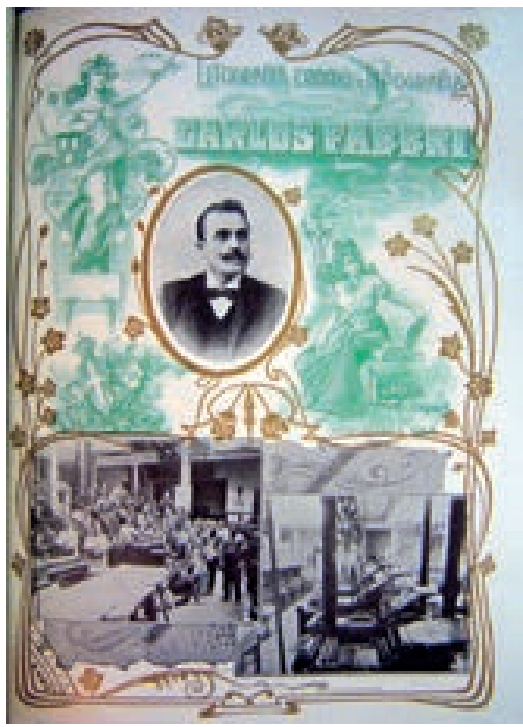

Imagen 11

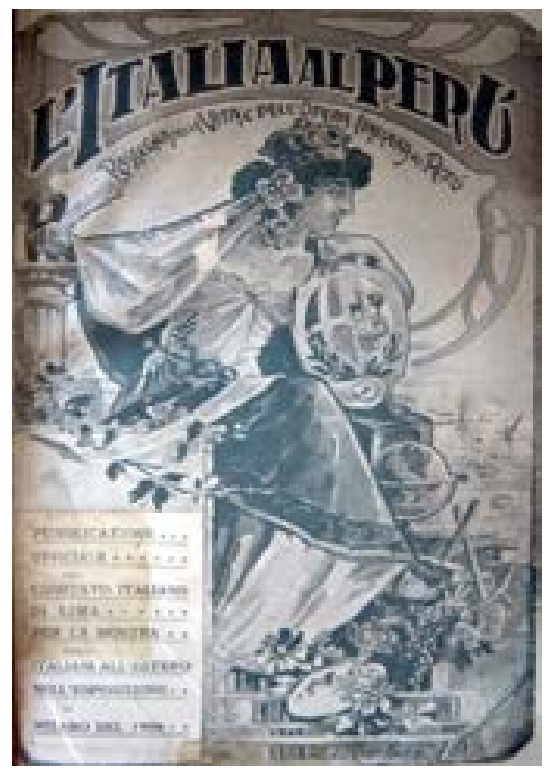

Imagen 12 
que Fabbri sea un activo miembro de la comunidad italiana afincada en el Perú. Fue socio de la Compañía de Bomberos Roma N 1 y de la Sociedad Italiana de Beneficencia; en 1910, presidió el Club Italiano, y fue un entusiasta anfitrión en un concierto y baile en honor del rey Víctor Manuel III.

Se concluye este artículo con un magnífico ejemplo de la calidad representativa y de impresión de su tipolitografía. Ello se puede ver fusionado en L'Italia al Perú, libro que plasma, entre otros, la activa labor de los italianos en suelo peruano. En su carátula (imagen 12), Fabbri dispone a una imponente italiana coronada, rodeada de diversos objetos relacionados con la ciencia y el arte — globo terráqueo, paleta y pinceles_ quien, con la mirada hacia el mar, descansa su brazo izquierdo sobre un escudo ítaloperuano; de este modo, fusiona la sapiencia de ambos países. En la mano derecha, tiene una pluma dispuesta a escribir o, quizá, a dibujar sus experiencias al otro lado de la orilla. Carlo Fabbri fallece el 13 de febrero de 1940. Su vida, tal como el escudo de la matrona, estuvo dividido en dos países: Italia, su tierra natal donde pasó sus años de infancia y juventud, y el Perú, la tierra en la que alcanzó el éxito, formó familia y murió.

Recibido: 11 de mayo del 2017

Aprobado: 16 de agosto del 2017

\section{Bibliografía}

BONFIGLIO, Giovanni

1994 Los italianos en la sociedad peruana: una visión histórica. Lima: Asociación Italianos del Perú.

EL COMERCIO

1926 "La litografía y tipografía Carlos Fabbri”. El Comercio. Lima, 18 de octubre, p. 1. 
1910 “Crónica”. El Comercio. Lima, 16 de julio, p. 1.

ILUSTRACIÓN PERUANA

1910 "En el club italiano". Ilustración Peruana. Lima, número 59, 16 de noviembre, p. 622.

LA ILUSTRACIÓN SUD AMERICANA

1891 "Nuestros grabados". La Ilustración Sud Americana. Lima, número 1, 1 de setiembre, p. 39.

LEONARDINI, Nanda

2003 El grabado en el Perú republicano. Diccionario histórico. Lima: Cenpro Editorial e Imprenta de la UNMSM.

1998 Los italianos y su infuencia en la cultura artística peruana en el siglo XIX. Tesis doctoral. México, Universidad Nacional Autónoma de México.

LITOGRAFÍA Y TIPOGRAFÍA FABBRI

1906 "Anuncio Litografía Cromo y Tipografía Carlos Fabbri." L'Italia al Perú. Lima: s/p.

PACHAS MACEDA, Sofía

2009 Evaristo San Cristóval. Visión gráfica de una época [catálogo]. Lima: Seminario de Historia Rural Andina de la UNMSM.

SACCHETTI, Alfredo

1906 L'Italia al Perú: rassegna della vita e dell'opera italiana nel Peru. Lima: Lit. y Tip. Carlo Fabbri. sulta: 30 de setiembre de 2013. <www.wopc.co.uk/ peru/fabbri/index.html.>

TRISTÁN, Flora

2003 Peregrinaciones de una paria. Lima: Fondo Editorial de la Universidad Nacional Mayor de San Marcos. 
VELÁZQUEZ, Marcel

2009 "La República de papel: balance, problemática y proyecciones de los estudios sobre la prensa del siglo IX”. En VELÁZQUEZ, Marcel (compilador). La República de papel. Política e imaginación social en la prensa peruana del siglo XIX. Lima: Fondo Editorial de la Universidad de Ciencias y Humanidades, pp. 11-42.

VILCA, Elizabeth

2009 "La imagen femenina: una visión contradictoria en el discurso del sujeto ilustrado en El Correo del Perú (1872)". En VELÁZQUEZ, Marcel (compilador). La República de papel. Política e imaginación social en la prensa peruana del siglo XIX. Lima: Fondo Editorial de la Universidad de Ciencias y Humanidades, pp. 165192. 